\title{
Anti-Normativism Evaluated*
}

\begin{abstract}
I argue that recent attempts to show that meaning and content are not normative fail. The two most important arguments antinormativists have presented are what I call the "argument from constitution" and the "argument from guidance." Both of these arguments suffer from the same basic problem: they overlook the possibility of focusing on assessability by norms, rather than compliance with norms or guidance by norms. Moreover, I argue that the anti-normativists arguments fail even if we ignore this basic problem. Thus, we have not been given good reasons to think that normativism is false.

Keywords: meaning, content, normativity, normativism, theory of content, semantics
\end{abstract}

\section{Introduction}

Normativists regarding content hold that content is a normative matter, and analogously for normativists about meaning (Gibbard, 2012; Whiting, 2007, 2009; Millar, 2004; Brandom, 1994; Glock, 1992; McDowell, 1984; Kripke, 1982; Anscombe, 1981). Anti-normativists disagree (Glüer and Wikforss, 2013, 2009a,b; Glüer, 2002, 1999; Glüer and Pagin, 1998; Hattiangadi, 2009, 2007, 2006; Bykvist and Hattiangadi, 2007). I will focus mostly on normativism about content, but a lot of what I say will also apply to normativism about meaning. My goal is to defend normativism against recent attacks.

${ }^{*}$ The Version of Record of this manuscript has been published and is now available in The International Journal of Philosophical Studies, June 2015, http://www.tandfonline.com/10.1080/09672559.2015.1042398 
What is normativism? I think of normativism as a thesis in the foundational theory of content. Robert Stalnaker (1997) distinguishes descriptive semantics, which tells us what semantic values expressions of a language have, from foundational semantics, which tells us what determines the correct descriptive semantics for an actually used language. Such a distinction can be applied in the theory of content more generally. Normativists hold that normative facts necessarily covary with the correct descriptive theory of content for a given language or the mental states of a subject. ${ }^{1}$ Content-determining normativism (CD-normativism) holds that normative facts partially determine the correct descriptive theory; content-engendered normativism (CE-normativism) holds that the norms are merely a consequence of the correct descriptive theory. I will mostly focus on CD-normativism.

The debate doesn't concern what we may call "compositional semantics," i.e. a theory that articulates our tacit semantic competence. Normativism, as I understand it, is a claim about what anchors the technical concepts we use in our (compositional) theory of content, in something that we can understand independently of these technical concepts, where such an anchoring or explanation need not be reductive. The technical concepts we might want to use include "truth at a point," "reference," "assertability," "provability," "incompatibility," "inferential role," etc. Normativists claim that some concepts we need for stating the correct theory of content must be explained in terms of norms - typically norms governing linguistic or mental acts or states. ${ }^{3}$

Thus, normativism, in the CD version, is the view that we must explain the central concepts of our theory of content in terms of norms, and that normative facts are among the facts that determine the correct descriptive theory of

\footnotetext{
${ }^{1}$ Here I am ignoring the issue of non-factualism about normativity. Nothing in what follows hangs on this.

${ }^{2}$ Here I am drawing on work by John McFarlane (2014) and Seth Yalcin $(2011 ; 2014)$.

${ }^{3}$ This is, e.g., what I take MacFarlane (2005) to be doing when he tries to make sense of the notion of relative truth by connecting it to the aim or norms of assertion.
} 
content for a given language or the mental acts of a subject. Since this is how I see the issue, I will not discuss anti-normativist considerations of the following shape: "Normativists think that meaning is normative because meaningful expressions, beliefs, etc. have correctness conditions. However, 'correctness' is not a normative term here; it can be explained in terms of truth, reference, satisfaction, etc. So normativism fails." Such considerations simply assume what is at issue, namely that the central concepts of the correct semantic theory are non-normative.

I shall not argue for normativism; I merely defend it against some challenges. I will assume that there is a plausible initial motivation for normativism. What could the motivation be? There are different such motivations for different people. Some think, e.g., that facts about meaning can (non-instrumentally) justify the use of expressions and concepts. Speaking for myself, I am a normativist because I think that the concept of a good inference must play a crucial role in our theory of content. By "good inference" I do not mean a model-theoretic or proof-theoretic notion or anything the like. At best, such notions are attempts to codify an antecedent notion of inferential goodness or validity (see Field, forthcoming). The concept of inferential goodness must be explained, I think, in normative terms; we must say something about what inferences we should and should not make.

The paper is structured as follows: I first give a rough sketch of the two central arguments against normativism and explain why they suffer from the same basic problem (Section 2). I then look at the debate in more detail. I present the dialectic as starting with a challenge for the normativist, and I say how the normativist should react (Section 3). The anti-normativist then offers her two central arguments to back up her challenge; I show that these arguments are unsuccessful (Sections 4 and 5). 


\section{The Basic Problem with the Anti-Normativists' Arguments}

Different anti-normativists hold anti-normativism for different reasons. Some are motivated by the idea that anti-normativism is the only way to rescue us from semantic skepticism (Hattiangadi, 2007). Others seem motivated by the Davidsonian idea that the content of an utterance or mental state is the content that would be assigned to the utterance or state by an overall interpretation that makes the subject come out maximally (or sufficiently) rational (Glüer, 1999, 2000; Glüer and Wikforss, 2009a). ${ }^{4}$ Despite these very different projects, anti-normativists are united in attacking normativism. Thus, anti-normativism is best evaluated by looking at the arguments anti-normativists have presented. In this section, I sketch two central anti-normativist arguments and explain what I see as the fundamental problem with them. I do this very quickly; I go into more detail later on.

As far as I can see, the two most important arguments anti-normativists have presented are what I call "the argument from constitution" and "the argument from guidance." ${ }^{5}$ The argument from constitution goes like this (Glüer and Wikforss, 2009a, pp. 48-52): According to normativism, following particular norms is constitutive of having contentful mental states. Hence, we cannot violate these norms without ceasing to have contentful mental states, unless we are in mitigating circumstances. But norms that we cannot violate unless we are in mitigating circumstances are not genuinely normative. So normativism fails. A variant of the argument says that if a given expression or state having a certain content is constituted by the subject following a certain norm, the

\footnotetext{
${ }^{4}$ Let me briefly register where I disagree. Regarding the first motivation, I cannot see why normativism should make semantic skepticism unavoidable unless one adopts an error theory about normative judgments. Regarding the second motivation, I doubt that the criterion of (maximal) rationality can single out a unique descriptive theory of content.

${ }^{5}$ For what it is worth, those are the arguments that strike me as the strongest ones.
} 
subject cannot violate the norm unless she is in mitigating circumstances. So these "norms" are not genuine norms.

The argument from guidance goes like this (Glüer and Wikforss, 2009a, pp. 55-63): Normativists hold that every contentful state or act is the result of, or an instance of, the subject following a norm; the norm must guide the subject. But in order to follow a norm, the subject must have been in a different, and temporally prior, contentful state. Thus, a vicious regress ensues. A variant of this argument says that in order to create norms that could constitute facts about contentful acts and states, one needs some prior contentful acts or states.

Both of these arguments suffer from the same basic problem: anti-normativists overlook the possibility that norms can be constitutive of something without those who are subject to the norm being guided by the norm or being in accordance with the norm. One can think that divine commandments, e.g., are constitutive of morality while thinking that no one is guided by these commandments and everyone is violating them. Similarly, the claim that certain laws are constitutive of a legal system does not imply that anyone is guided by these laws or that anyone abides by them. Normativity is not always a matter of the first-person deliberative standpoint.

A plausible normativism holds, I think, that what partially constitutes facts regarding what someone means or what content a mental state has is that the subject is correctly assessable by certain norms. If an utterance or a mental state has a certain content, we can legitimately evaluate what the subject does in light of certain norms. ${ }^{6}$ And it couldn't have this content if the norms didn't apply. Neither the argument from constitution nor the argument from guidance gets any traction with such a view.

Regarding the argument from constitution, the normativist can say that

\footnotetext{
${ }^{6}$ I think the relevant norms here are norms of reasoning and norms of rational discourse.
} More on this below. 
someone who violates a norm outside of mitigating circumstances can nevertheless be assessable by the norm. And regarding the argument from guidance, the normativist can deny that every contentful act or state must be the result of, or an instance of, following a norm.

Anti-normativists might reply that the normativism I have in mind requires a conception of normativity that is very different from their conception. I am working with a third-personal, evaluative conception of normativity. They are interested only in norms that tell someone what to do - from a first-personal, deliberative standpoint (Glüer and Wikforss, 2013, p. 82). However, it is implausible to restrict the normative to a first-person standpoint. Judgments about what someone else should do are just as normative and prescriptive as judgments about what I myself should do. The nature of the normativity involved does not change just because the standpoint of assessment changes. Perhaps one sometimes has to follow a norm, or comply with the norm in sufficiently many cases, in order to fall under the norm. But norms like divine commandments and laws show that this need not always be so. If anti-normativists are not interested in normative assessments from the third-person standpoint, they cannot claim to have shown that content is not normative. If that is not their goal, that's great! But if it is, more work lies ahead of them. ${ }^{7}$

My sketch of the anti-normativists' arguments was very rough, and my reply was quick. So let us go through the dialectic more carefully. This will also give me a chance to highlight problems with the anti-normativists' arguments that are independent of the basic problem just outlined.

\footnotetext{
${ }^{7}$ Sometimes anti-normativists claim that some of their arguments apply not only to prescriptions but also to "pure evaluations, or norms concerning 'Sein-Sollen', not 'Tun-Sollen", (Glüer and Wikforss, 2009a, p. 32n4). Notice, first, that the distinction between "ought-todos" and "ought-to-bes" is not the distinction I am using. If I say "You ought to $\phi$," this is an "ought-to-do" but it is a third-personal assessment. This claim about what you ought to do can be true, whether or not you are guided by it. Second, the particular argument anti-normativists have in mind here is their response to what they call the "simple argument." Since I am not replying to the simple argument, I need not consider their response here.
} 


\section{The Anti-Normativist's Challenge}

We can think of the debate between normativists and anti-normativists as beginning with a challenge: the anti-normativist challenges the normativist to formulate the norms that are (allegedly) essential to content. In a second step, the anti-normativist argues that none of the normativist's proposals work. In this section, I want to focus on the first step. We can formulate the antinormativist's challenge as an argument.

Argument A:

(A.P1) If content (meaning) is normative, a sentence of the form " $S$ 's mental state $M$ has content $C$ " (" $S$ means $F$ by $t$ "), perhaps together with some non-normative statements, implies something of the form " $S$ ought/may (not) $\phi "$.

(A.P2) " $S$ 's mental state $M$ has content $C$ " (" $S$ means $F$ by $t$ ") implies nothing of the form " $S$ ought/may (not) $\phi$," not even together with some non-normative statements.

(A.C) $\quad \therefore$ Content (meaning) is not normative.

It is crucial to be clear about what kind of norm anti-normativists think is required to falsify (A.P2): First, the force of the norm must not depend on any antecedent desire (Glüer and Wikforss, 2009b; Hattiangadi, 2006, p. 228). Second, the norm must spell out a genuinely semantic obligation (Glüer and Wikforss, 2009a, pp. 35, 38; Hattiangadi, 2006, p. 237). Third, the norm must guide the linguistic behavior or reasoning of the agent (Glüer and Pagin, 1998; Glüer and Wikforss, 2009a, p. 32). Call these conditions the three "oughtconditions."

With these conditions in place, anti-normativists argue against particular principles that connect meaning-claims to ought-claims; e.g.: 

$S$ means $F$ by $t \rightarrow(x)[S$ ought (to apply $t$ to $x \leftrightarrow x$ is $F)]$. For all $S$ and $p: S$ ought to believe that $p \leftrightarrow p$ is true.

Anti-normativists are right to reject these particular principles. This does not show, of course, that (A.P2) is true. Thus, the argument is a challenge to formulate norms that falsify (A.P2).

\section{Evaluating Argument A}

The debate about normativism has focused mostly on (A.P2). Before I turn to this debate, however, I want to note that the normativist might reject (A.P1). One reason why anti-normativists think that they can presuppose (A.P1) is that many normativists accept it. Kripke, e.g., famously claimed that meaning something by a sign must be such that, when suitably queried, "whatever in fact I (am disposed to) do, there is a unique thing that I should do" (Kripke, 1982, p. 24). However, the normativist need not follow Kripke here. An analogy can help to bring this out.

We can, to a first approximation, think of the claim that meaning is normative in analogy to the claim that money is normative. The latter claim is naturally interpreted as saying: We cannot explain what money is without appealing to norms, and normative facts are among the facts that determine the correct descriptive theory of who has what amount of money. The moneynormativist might think, e.g., that we must appeal to norms governing property, which are typically genuinely prescriptive (and not, e.g., of the form " $x$ counts as $y$ in $C^{\prime \prime}$ ), in order to explain what money is. And she may think that the facts that determine who has what amount of money include facts regarding who has a right to what. Must the money-normativist claim that statements like " $S$ has a twenty-dollar bill in her pocket" imply statements of the form " $S$ ought/may (not) $\phi ” ?$ It does not seem so. According to money-normativism, what makes 
something money is, inter alia, the role it occupies in a network of norms. It does not follow that individual statements about particular amounts of money always have normative implications. Similarly, the normativist about content can say that what makes something a contentful act or state is, inter alia, the role it occupies in a network of norms. It does not follow that statements of the form " $S$ means $F$ by $t$ " or " $S$ 's mental state $M$ has content $C$ " always have normative implications.

One important difference between the cases is that there can be contentful thought and talk before money is around, while this is not so for content. I don't think this is a problem for the normativist. It will be more fruitful, however, to look at this issue in the context of (A.P2). So let's grant (A.P1) and answer the challenge directly by rejecting (A.P2).

My aim here is not to provide a normativist foundational theory of content. Rather, I want to give an example of what I take to be normative facts that falsify (A.P2), namely normative facts about reasoning. Claims about the contents of, e.g., beliefs imply proscriptions, namely proscriptions to reason in certain ways:

For every believable content $C$, there are ways $W$ such that, if subject $S$ 's belief $B$ has content $C$, then $S$ must not reason in ways $W$ with $B$ (with possible exceptions in special circumstances).

I don't think that (N3) is the only principle that falsifies (A.P2), but it will serve well as an illustration. ${ }^{8}$ The truth of (N3) follows from two plausible premises: First, for every possible belief, there is a way to reason fallaciously with the belief, and which pieces of reasoning are fallacious depends on the content of the belief. Second, you must not reason fallaciously. The principle allows that there

\footnotetext{
${ }^{8}$ The application of (N3) to Kripke's famous case of quaddition is straightforward: If Kripke means addition, and not quaddition, by "+", he may not reason in such a way that his result for the query "What is $57+68$ ?" is " $5 . "$
} 
are special circumstances in which you may reason fallaciously, but normally you must not. If you reason fallaciously, you are open to legitimate criticism. You cannot block this criticism by pointing out that you don't have certain desires. Reasoning fallaciously is irrational, and calling someone "irrational" is a genuinely normative evaluation. Thus, (N3) is true and spells out genuine normative consequences of content ascriptions. Moreover, (N3) does not depend on any particular theory of content.

Anti-normativists have considered and rejected norms like (N3). As far as I can see, they have five objections that we can apply, with slight adjustments, to (N3). The two most important objections are versions of the argument from constitution and the argument from guidance: Proscriptions like the one in (N3) are constitutive of the beliefs involved and, hence, cannot be violated outside of "mitigating circumstances" (Glüer and Wikforss, 2009a, p. 51).

(ii) Norms governing reasoning cannot be "rules in anything like the sense we are interested in: prescriptions capable of guiding an activity or performance" (Glüer and Wikforss, 2009a, p. 48).

I will discuss these points in the next two sections. In addition to these major objections, anti-normativists have three smaller points:

(iii) The proscription in (N3) is not genuinely semantic (Glüer and Wikforss, 2009a, p. 38); it derives from the norm of rationality that you must not reason fallaciously.

(iv) Saying that something is irrational is not a genuinely normative evaluation. If a subject reasons fallaciously, "the subject is being irrational, but it is a further question whether holding an irrational 
belief is wrong in the sense of violating a norm" (Glüer and Wikforss, 2013, p. 91).

Norms of reasoning, and the like, cannot determine the full set of truth or satisfaction conditions for an expression or mental state (Hattiangadi, 2007, p. 206). Norms that are strong enough to do that lead to obligations no one can fulfill.

In this section, I want to discuss only points (iii)-(v). With respect to point (iii) it is important to keep in mind what the CD-normativist is trying to do: she wants to connect normative facts about, e.g., reasoning, assertion, belief, etc. to facts about what the correct descriptive theory of content for a given subject or community is. It cannot be an objection to this idea that facts about content make contact with normative facts only via pragmatics or the theory of rationality. That is simply part of normativism. The CD-normativist thinks that in order to make sense of our theory of content and to determine whether it is adequate, we must look at the connection between the theory of content and the theory of rationality or pragmatics. ${ }^{9}$

The anti-normativist might respond that my reply to point (iii) depends on me favoring CD-normativism, which says that norms partially determine the contents of utterances and thoughts, over CE-normativism, which says that the content is determined independently and merely gives rise to the norms in question (Glüer and Wikforss, 2009a,c). They may think that, on CE-normativism, (N3) is like the norm: "If you are so heavy that sitting on someone else would kill that person, you must not sit on anyone." Satisfying the antecedent is a straightforwardly non-normative matter. The normative force of the statement derives from the norm that you must not kill anyone. Similarly, the anti-normativist may think that the fact that $S$ 's belief $B$ has content $C$ is a non-normative

\footnotetext{
${ }^{9}$ Glïjœer and Wikforss seem to implicitly acknowledge this when they raise objections like point (iii) only against CE-normativism and not against CD-normativism.
} 
matter. The normative force of (N3) depends on the norm that you must not reason fallaciously (Glüer and Wikforss, 2015; Hattiangadi, 2006). However, that's not plausible. Compare the norm "If doing $\phi$ would be coward, then you must not do $\phi . "$ Is it plausible that something being coward is a non-normative fact and that the norm derives its force from the norm that you must not do what is vicious? No. What makes the action bad is first and foremost that it is coward, and we can connect its cowardice to other vices by saying that the act is vicious. Similarly, for a CE-normativist, a piece of fallacious reasoning is bad first and foremost because it involved such-and-such contents in such-and-such a way. To call it a fallacy does not specify the deeper ground of the badness; it merely connects this particular piece of reasoning with other pieces of reasoning that are also bad. By contrast, in the case of sitting on someone, what makes the action bad is first and foremost that it is an act of killing someone. So (N3) is like the norm concerning cowardice and not like the norm concerning obesity. Thus, objection (iii) fails not only against CD-normativism but also against CE-normativism.

This brings us to point (iv), i.e., the claim that assessments in terms of rationality are not genuinely normative. Anti-normativists try to defend this surprising thesis by providing a non-normative conception of rationality.

Strictly speaking, on our account reasons are (true or false) propositions. Having such a reason is simply to believe the relevant proposition. [...] The reasons themselves, the propositions that are the contents of the relevant beliefs, stand in inferential or evidential relations. And beliefs stand in reasons relations because their contents stand in these relations; reasons relations between beliefs 'piggy-back' on the inferential or evidential relations their contents stand in. [...] With reasons relations thus in place, we can then say that it is rational for a subject $S$ to believe that $p$ iff $p$ is evidentially supported (to a sufficient degree) by the reasons the subject 
has. Rationality in general thus becomes a matter of the degree to which a subject's beliefs in fact instantiate the pattern of evidential relations between their contents. (Glüer and Wikforss, 2013, pp. 90-91)

This conception of rationality presupposes that we don't have to bring in norms of reasoning in order to explain the contents of beliefs or the "inferential" and "evidential" relations between these contents. Clearly, the CD-normativist will deny this. So the argument is question-begging against CD-normativism. But the problem with this argument against the normativity of rationality runs deeper. To see this, notice that a parallel argument could be used to show that morality is not normative: "The belief that $p$ and the intention to $\phi$ stand in the being-a-moral-reason-to relation because their contents stand in an appropriate relation of moral support. It is moral for a subject to intend to do $\phi$ iff the content of the intention to $\phi$ is morally supported (to a sufficient degree) by the reasons the subject has. Being moral is a matter of the degree to which a subject's beliefs and intentions instantiate the pattern of moral support relations between their contents." Clearly, these considerations don't show that morality is not normative. The pattern would not be a pattern of moral support if it were permissible to reason practically about a relevant topic without instantiating it. That's where the normative force of morality shows up. Similarly, the relations of inferential and evidential support would not be such relations if it were okay not to instantiate (any of) them when reasoning theoretically. You shouldn't reason fallaciously. Whatever the anti-normativist says about relations between contents, she is not characterizing rationality adequately if she leaves it open whether you should be rational. In fact, rationality seems to be normative in many respects: we should be rational and avoid being irrational, being rational is a human good, we should promote the rationality of ourselves and others, and saying that someone is irrational is a criticism. So objection (iv) fails. 
What about point (v), i.e., the claim that norms of reasoning cannot settled truth/satisfaction conditions? CE-normativists obviously need not deny this. And the same goes for CD-normativism. CD-normativism claims that normative facts are among the facts that determine the correct descriptive theory of content for a given language or mental economy. It is not the claim that normative facts are sufficient to determine the correct descriptive theory.

With these three minor points out of the way, we can return to the two central arguments against normativism.

\section{The Argument from Constitution}

In response to (A.P2), I have suggested that facts about the contents of one's beliefs imply proscriptions to reason with these beliefs in certain ways. Antinormativists have rejected proposals like this. The idea behind their argument is that norms of rationality cannot be genuinely normative because they are constitutive of having contentful mental states (Glüer and Wikforss, 2009a, pp. 46-52). According to Kathrin Glïiœer and Asa Wikforss, this follows from two claims: First, if your acts and states are not in accordance with the norms of rationality and you are not in "mitigating circumstances," you are not a believer and, hence, the norms of rationality do not apply to you. So you cannot violate the norms of rationality if you are not in "mitigating circumstances." Second, "oughts not only imply cans, they also imply the possibility of violation," and, in particular, it must be possible to violate a norm outside of "mitigating circumstances" (Glüer and Wikforss, 2009a, p. 49).

Argument B:

(B.P1) If $S$ 's acts and states being in accordance with norms $N$ is constitutive of $S$ having contentful mental states, then it is impossible for 
$S$ 's acts and states to violate $N$, unless $S$ is in "mitigating circumstances."

(B.P2) $S$ 's acts and states being in accordance with the norms of rationality (when not in "mitigating circumstances") is constitutive of $S$ having contentful mental states.

(B.P3) If norms $N$ are genuinely normative for $S$ 's acts or states, $S$ 's acts and states can violate $N$ without $S$ being in "mitigating circumstances."

(B.C) $\quad \therefore$ The norms of rationality are not genuinely normative.

Anti-normativists also think that there is a further problem with the idea that the norms of rationality are constitutive of contentful states. "If the 'rules' of rationality are constitutive of thought in general, no-one can decide to follow, or be motivated by, these 'rules"' (Glüer and Wikforss, 2009a, p. 47). This point has to do with the fact that anti-normativists don't count a norm as genuinely normative unless it guides performances. I will discuss this issue in the next section.

\section{Evaluating Argument B}

How should the normativist react to Argument B? Regarding the second premise, the normativist should not hold that the relevant norms are constitutive in the sense of (B.P2). The normativist should hold that what (partially) constitutes that $S$ has contentful mental states is not that $S$ 's acts and states are in accordance with the norms of rationality, but that $S$ 's acts and states are subject to, fall under, are assessable by these norms.

If we work with this claim about constitution, the analog for the first premise, (B.P1), does not hold. To see this, suppose we stipulate that something is a $K$ 
just in case it falls under norm $N$. Falling under norm $N$ is, thus, constitutive of being a $K$. Does it follow that every $K$ that is not in accordance with $N$ is in "mitigating circumstances"? Clearly not. Moreover, it is implausible to think that $S$ has contentful mental states only if $S$ 's act and states are in accordance with the norms of rationality unless she is in "mitigating circumstances." After all, if being out of line with the norms of rationality just once while outside of "mitigating circumstances" implies that you don't have contentful mental states, it is next to impossible to tell whether anyone has contentful mental states.

What matters is assessability by the norms and not compliance with them. As already intimated in Section 2, this is the basic problem with anti-normativist arguments. Let's put it to one side. Let's grant, for the sake of argument, that constitution by normative facts is a matter of being in accordance with norms. Is the argument from constitution convincing if we ignore its basic problem?

Perhaps what Glï;œer and Wikforss really mean is that if following a rule $R$ in most cases is constitutive of being, say, a $K$, there must be circumstances under which a $K$ cannot fail to act in accordance with $R$. But that can't be right. Call somebody a " $K$ " iff she follows rule $R$ in more than $95 \%$ of the cases. Is there any particular action and any particular circumstances such that it is impossible for a $K$ not to perform the action under these circumstances, without ceasing to be a $K$ ? Obviously not! In any particular case, a $K$ can do anything, as long as she follows the rule in enough other cases.

Perhaps Glïœer and Wikforss don't think that such a principle is true in general but that there are such special circumstances for the particular case of rules of rationality, like (N3). They say:

[T] here might be further conditions such that a subject fulfilling them, and believing that $p$ and that if $p$ then $q$, cannot fail to believe that $q$. That there in fact are such conditions is very plausible even if definitive lists might prove elusive. After all, the question whether to believe $q$ is 
simply settled once I am completely awake, fully aware of all the relevant beliefs at the same time, and give it all my attention - provided, at least, that the relevant beliefs are not too numerous or too complicated. No prescription is required to establish the connection, and no prescription can be violated. (Glüer and Wikforss, 2009a, p. 50)

Is it really plausible that there are such conditions? I don't think so. As the psychological literature on reasoning shows (e.g. work on the Wason Selection Task), people fail to draw easy, immediate inferences even if they are completely awake, fully aware of all relevant beliefs, and give the task all their attention (for an introduction see Johnson-Laird, 2006). Of course, there might be circumstances that make it nomologically necessary for the subject to reason correctly. If that is the right reading of "mitigating circumstances" in (B.P1), however, we must also read (B.P3) in this way. But it is certainly false that if norms $N$ are genuinely normative for $S$ 's acts or states, then $S$ 's acts and states can violate $N$ when it is nomologically necessary for $S$ 's acts and states to be in accordance with $N$. There simply seems to be no reading of (B.P1)-(B.P3) under which Argument B is sound.

What about (B.P3) by itself? Glïßœer and Wikforss claim that if the rules of rationality are genuinely prescriptive, then it must be possible to violate these rules outside of "mitigating circumstances."

If a putative prescription can only be violated under 'mitigating circumstances' like ['cognitive overload' and the like], the forbidden combinations thus realized would therefore not be of the right kind, the kind required by prescriptivity. [...] for instance the prescription that forbids resting your elbows on the table while dining in company. Would we think such a prescription was in force for us if we could 'violate' it only when half asleep or not paying any attention to what we are doing? Quite clearly not. And the same holds for any putative prescription to the effect that 
subjects believing that $p$ and that if $p$ then $q$ ought to believe that $q$. Assume that there is such a prescription. The principle that ought implies the possibility of violation requires that it could be violated even by a calm, fully awake subject with rather simple states of mind. But it cannot. (Glüer and Wikforss, 2009a, p. 50)

I see no reason to accept the idea that it must be possible to violate norms outside of "mitigating circumstances." Suppose I can only murder someone in the heat of the moment if I am in mitigating circumstances for murdering someone in the heat of the moment. Does this show that the rule "Don't murder anyone in the heat of the moment" cannot be in force for me? If by "mitigating circumstances" we mean circumstances such that I cannot be sanctioned or punished for my act of murder in any way, the rule seems pointless. When we look at rules of rationality, however, this is not the situation we are in. It is simply not true that you can violate the rules of rationality only if your circumstances are such that you cannot legitimately be criticized for being irrational. That would indeed make such rules pointless. In fact, however, people often reason fallaciously and are, thereby, subject to legitimate criticism. Hence, we must reject (B.P3).

We have seen that the argument from constitution fails even if we ignore the basic problem that it focuses on compliance instead of assessability. I have ignored the issue of guidance. So let's turn to what is perhaps the ultimate stronghold of anti-normativism: the problem of guidance.

\section{The Argument from Guidance}

Anti-normativists think that normativists are committed, if their thesis is at all interesting, to the claim that the relevant norms guide subjects in their thought or talk. Different anti-normativists think this for different reasons. For Anandi 
Hattiangadi (2007) the normativist must think this because Hattiangadi's normativist defends semantic skepticism. Since I have no interest in defending semantic skepticism, I shall ignore this idea. Glïœeer and Wikforss think that the requirement of guidance derives directly from the requirement that the relevant norms be prescriptive.

Along with almost everyone else in this discussion, we take the relevant normativity to be prescriptive in nature. Prescriptions, we take it, involve genuine 'oughts'; their very point is to guide our performances. (Glüer and Wikforss, 2009a, p. 32)

And in a paper on the normativity of belief they say:

[T] he normativist could abandon guidance - and thereby genuine prescriptivity - in favor of some other, novel construal of normativity. Since we are only concerned with genuine prescriptivity, that would amount to accepting the conclusion of this paper. (Glüer and Wikforss, 2013, p. 82)

The idea seems to be that merely being in accordance with a norm is not a genuinely normative matter. In order to be genuinely normative, something must be a matter of rule-following and not merely of being in accordance with a rule (Glüer and Wikforss, 2009a, p. 55). But to follow a rule, the rule must guide the subject (Glüer and Pagin, 1998).

Intuitively, what is required for following a rule $R$ is that the performances in question can be explained by reference to $R$. This explanation is available because $S$ herself takes a certain attitude to $R$. [...] On a very natural reading, this simply means that $R$ plays a role in the motivation $S$ has for what she does. [... I ]n order to be motivated by $R, S$ needs to have a pro-attitude towards what is in accordance with $R$. (Glüer and Wikforss, 2009a, p. 55) 
This leads to what Glï;œer and Wikforss call the "dilemma of regress and idleness" (Glüer and Wikforss, 2009a, p. 54). If the norms that the normativist cares about figure in an explanation of all contentful acts and states, this launches us on a vicious regress. After all, the pro-attitude towards what is in accordance with $R$ is a contentful state. So a kind of normativism on which the content of all intentional states is determined by norms "cannot, on pain of vicious regress, construe any kind of intentional mental state as a condition on rule-following" (Glüer and Wikforss, 2009a, p. 57). But, anti-normativists continue, something that does not require an intentional mental state cannot be a case of rule-following. And if contentful acts and states are not cases of, or the results of, rule-following, calling the standards in question "normative" is idle.

Argument C:

(C.P1) The norms to which the normativist appeals must either guide all of the subjects contentful acts and states or they are not genuinely normative.

(C.P2) If the relevant norms guide a contentful act or state of the subject, the subject must have enjoyed a prior contentful act or state that explains the act or state that is under the guidance of the norm.

(C.P3) It is impossible that every contentful act or state requires infinitely many prior contentful acts or states.

(C.C) $\quad \therefore$ The norms to which the normativist appeals are not genuinely normative.

\section{Evaluating Argument C}

Here again we encounter the basic problem from Section 2: anti-normativists focus on guidance and not on assessability. If we focus on assessability, we 
should reject the third ought-condition and, hence, (C.P1). Indeed, I hold that there are genuine norms, even prescriptive norms, that are not action-guiding (see Bridges, 2014; Ginsborg, 2012). ${ }^{10}$ Divine commandments, norms regarding emotions, and laws are genuinely normative and prescriptive; but they don't necessarily guide our performances. In fact, it seems that norms regarding what emotions we should feel, e.g., cannot guide us in feeling these emotions. Antinormativists, however, think that calling a standard "normative" that cannot guide anyone's compliance with it is merely to apply an idle label (Glüer and Wikforss, 2009a, p. 60). To see that this is wrong, consider the following rule:

(R) In everything you do, always be guided and motivated by the features of your act that make it right, except where they include (R), in which case you should do it without being motivated or guided by $(\mathrm{R})$.

It is in principle impossible for rule $(\mathrm{R})$ to guide and motivate acts that are in accordance with $(\mathrm{R})$. But that does nothing to show that $(\mathrm{R})$ cannot be a genuine norm. After all, it might be true that we ought to do the right thing for the reasons that make it right unless that would involve some kind of rulefetishism. Rejecting the guidance-requirement does not make normativism an empty claim. Rather, everyone should agree that, in general, not all genuine norms are guiding someone's performances. Acknowledging this does not require a "novel construal of normativity" (Glüer and Wikforss, 2013, p. 82). All it requires is the realization that not all norms must, can, or are meant to be applied in first-personal deliberation. If acknowledging this basic fact about norms means that I am "accepting the conclusion" of anti-normativism (Glüer

\footnotetext{
${ }^{10}$ Sellars already made a related point, when he wrote: "The point I wish to make is the obvious one that if a species of linguistic episode is not a doing in the practical sense, a performance, then the relevant rules must be rules of criticism rather than rules of performance" (Sellars, 1967, p. 271). After all, norms of criticism don't necessarily guide the behavior of the person who is performing the act that is the potential target of the criticism.
} 
and Wikforss, 2013, p. 82), this suggests that the conclusion of anti-normativism cannot be as interesting as it appears to be when formulated as "neither meaning nor content are normative."

However, let us again ignore this basic problem for the sake of charity. Is the argument from guidance convincing once we grant, for the sake of argument, that rule-following and guidance must play a crucial role in the constitution of content or meaning?

Anti-normativists seem to think it's a problem that we cannot formulate the relevant norms before we bring ourselves under them (Glüer and Wikforss, 2009a, p. 60). No one can have a pro-attitude towards bringing herself under these norms before actually bringing herself under them. But why should this be a problem? Perhaps the anti-normativist thinks that the relevant norms must be of our own making and that we cannot make these norms unless we can think and talk about them before making them. Firstly, however, it is not clear why the normativist must hold that the relevant norms are of our own making. Of course, the normativist must hold that what normally leads to someone being able to think and talk meaningfully is, under normal circumstances, sufficient to bring the subject under the relevant norms. That does not imply, however, that we make the norms. Secondly, it is not clear why the norms cannot be of our own making if we cannot think and talk about them before making them. There is a sense in which thinking and talking are of our own "making," but we could not think and talk before we "made" thought and talk. So there must be a sense in which we can "make" something without thinking or talking about it before we "make" it. The normativist can hold that we "make" the norms that underwrite normativism in this sense - whatever that turns out to be.

Perhaps the anti-normativist's real worry is that the norms that underwrite normativism can, in principle, never guide anyone's states or acts - "you cannot 
even intend to follow" them (Glüer and Wikforss, 2009a, p. 60). There are two quick responses available to the normativist. Firstly, it has been doubted, on entirely independent grounds, that rule-following requires an intention to conform to the rule. ${ }^{11}$ Secondly, the anti-normativist assumes that the normativist must say that all intentional acts and states are cases of, or results of, rule-following. The normativist can reject (C.P1), however, and hold that what matters is not following the norms in every case but following them in sufficiently many, or in certain, cases. ${ }^{12}$ In fact, if the normativist thinks that the relevant norms crucially include norms of reasoning (as I do), it is plausible that not all contentful acts and states are the result of following these rules. After all, not all contentful acts and states are the result of reasoning. ${ }^{13}$ That does not mean that the contents of one's mental states cannot be (partially) determined by norms one follows in one's reasoning.

In an attempt to rescue (C.P1), the anti-normativist might say that her target is really the claim that all contentful acts and states are cases of, or results of, rule-following. If that is right, anti-normativism is often misleadingly framed as a claim about the normativity of meaning and content, and the normativist is free to concede the point. However, the normativist need not do so. For if we understand Argument $\mathrm{C}$ as an argument for the claim that there must be contentful acts or states that are not cases of, or results of, rule-following, this shifts all the weight to premise (C.P2). The anti-normativist must hold that

\footnotetext{
${ }^{11}$ Masahiro Yamada (2010, p. 296) writes "it is not at all clear that rule-observing requires any intention to conform to the rules. In fact, it is not even clear that a mental representation of the rule is required - witness the enormous difficulties we typically have in spelling out the finer details of social norms even though we have no difficulties observing them."

${ }^{12}$ We can think this even if we focus on assessability and not guidance. For perhaps following the rule in sufficiently many cases can make it the case that acts of the relevant kind are assessable by the norm.

${ }^{13}$ Anti-normativists formulate CD-normativism thus: "The content of a subject $S$ 's thoughts is determined by the rules governing $S$ 's reasoning" (Glï œœer \& Wikforss 2009a, p. 54). This does not imply that all of $S$ 's thoughts are the product of reasoning or the result of rulefollowing, contrary to what Glïßœer and Wikforss implicate (Glüer and Wikforss, 2009a, p. $57)$.
} 
there is no interesting notion of rule-following on which rule-following does not always require a prior contentful act or state (Glüer and Pagin, 1998; Glüer, 2002). I want to end this paper by suggesting that this is implausible.

Anti-normativists think that in order to follow a rule, your performance must be the result of a practical inference in which the rule occurs in the content of the premises. Let's begin with two reasons why the anti-normativist's picture of rule-following is too restrictive: First, empirical psychology tells us that we can, e.g., learn to follow the rules of an artificial grammar without having any (explicit) inkling regarding their content. In such cases, we follow a rule without the rule figuring in our (explicit) practical reasoning (for an overview see Pothos, 2007). Second, the anti-normativist's picture of rule-following makes it impossible to follow, e.g., the rule of modus ponens. On the anti-normativist's picture, following this rule must be the result of a practical inference like this one: "I want to follow modus ponens in my reasoning. Concluding that $p$ would be in accordance with modus ponens. So, I shall conclude that $p . "$ Now, if the conclusion of this inference itself amounts to concluding that $p$, this conclusion was not reached by modus ponens and the agent did not follow the rule of modus ponens, after all. If, on the other hand, the conclusion of this inference does not amount to concluding that $p$, then this concluding must be the result of another inference. But then, by anti-normativist's lights, the concluding cannot be an instance of following modus ponens. So, on the picture implicit in (C.P2), it is impossible to follow the rule of modus ponens. But it is implausible that there is no sense in which we can follow the rule of modus ponens. Thus, the picture of rule-following at work in Argument $\mathrm{C}$ must be flawed. The anti-normativist might reply that her picture of rule-following is the only one that can distinguish (in a reasonable way) between genuine rule-following and merely acting in accordance with a rule. There really isn't any alternative (Glüer and Pagin, 
1998; Glüer, 2002).

This is not the place to expound a theory of rule-following, but I think there is an alternative. Following rule $R$ is sometimes different from merely acting in accordance with rule $R$ in virtue of the fact that the subject tries to get it right, to do what is correct according to $R$, where this trying is not a matter of having any prior or independent attitude towards $R$. Surely, the anti-normativist will reply that you cannot try to do something without a representation of what you are trying to do figuring in your practical reasoning. But that must be wrong. After all, in making a practical inference, one is trying to do so correctly. Otherwise one wouldn't have failed by one's own lights when one makes a mistake in reasoning practically. If this required another practical inference, a vicious regress would ensue. Therefore, there must be a way of trying to do something correctly, of trying to get it right, that does not require that the act is the result of a practical inference. Indeed, your trying to reason correctly just is your reasoning.

Anti-normativists might reply that even if reasoning can be a case of rulefollowing without requiring any prior practical reasoning, it requires prior intentional states. It's impossible that all such states are the result of reasoning. The normativist can hold, however, that they are all cases of "trying to get it right." After all, when you judge, you are trying to judge truly. And this is so although judging that $p$ does not require you to first form the judgment that judging that $p$ would be to judge truly. It might be difficult to understand how this is possible, but it seems plainly true that when you judge, you try to judge truly and that does not imply that you first formed the belief that judging as you did is to judge truly.

The anti-normativist will object: trying to do something requires that one acts intentionally. But you cannot act intentionally if you didn't already have 
contentful mental states. So how can trying to do something be constitutive of having contentful mental states? I doubt that the fact that if I am reasoning, I am trying to reason correctly, shows that reasoning is an intentional action. But we can even grant this point if we wish. In the objection, all the work is done by the "already." If the fact that $p$ requires that it was already the case that $q$, it's implausible that $q$ is constituted by $p$. The mere fact, however, that if $p$, then $q$, does nothing to undermine such a claim. And, surely, we can act intentionally without having any prior intention. Thus, we can say that when you engage in reasoning and judging for the first time, you also try to reason and judge correctly for the first time, and you have contentful mental states for the first time: all of this comes on the scene together. (Actually, I am not sure that it really makes sense to speak about the first piece of reasoning or judgment you ever performed in your life; it seems more plausible that this is a case where we should say: "light dawns gradually over the whole.")

So the argument from guidance fails even if we ignore the basic problem with the argument. It is not only unclear why the normativist should have any special interest in guidance, but even if the normativist has such an interest, the anti-normativist's conception of rule-following is implausibly restrictive.

\section{Conclusion}

I have argued that there is a basic problem with anti-normativists' considerations: they overlook that normativists may focus on assessability by norms and not on norm-compliance or guidance. Moreover, I have argued that even if we ignore this basic problem, the arguments anti-normativist have put forward still fail. So, assuming that the initial motivation for normativism is plausible, normativists are in good standing. I have not tried to show that normativism is true. What I have argued is that we have not been given good reasons to 
believe that normativism is false.

\section{References}

Anscombe, G. E. M. (1981). Rules, rights and promises. In G. E. M. Anscombe (Ed.), The collected philosophical papers of G.E.M. Anscombe (vol. III), pp. 97-103. Oxford: Blackwell.

Brandom, R. B. (1994). Making It Explicit: Reasoning, Representing, and Discursive Commitment. Cambridge, Mass.: Harvard University Press.

Bridges, J. (2014). Rule-following skepticism, properly so called. In J. Conant and A. Kern (Eds.), Varieties of Skepticism: Essays after Kant, Wittgenstein, and Cavell, pp. 249-288. Berlin, Boston: de Gruyter.

Bykvist, K. and A. Hattiangadi (2007). Does thought imply ought? Analysis $67(4), 277-285$.

Field, H. (forthcoming). What is logical validity? In C. Caret and O. Hjortland (Eds.), Foundations of Logical Consequence. Oxford: Oxford University Press.

Gibbard, A. (2012). Meaning and Normativity. Oxford: Oxford University Press.

Ginsborg, H. (2012). Meaning, understanding and normativity. Aristotelian Society Supplementary Volume 86(1), 127-146.

Glüer, K. (1999). Sprache und Regeln: zur Normativität von Bedeutung. Berlin: Akademie Verlag.

Glüer, K. (2000). Bedeutung zwischen norm und naturgesetz. Deutsche Zeitschrift für Philosophie 48(3), 449-468. 
Glüer, K. (2002). Explizites und implizites Regelfolgen. In U. Baltzer and G. Schönrich (Eds.), Institutionen und Regelfolgen, pp. 157-175. Paderborn: Mentis.

Glüer, K. and P. Pagin (1998). Rules of meaning and practical reasoning. Synthese 117, 207-227.

Glüer, K. and A. Wikforss (2009a). Against content normativity. Mind 118(469), 31-70.

Glüer, K. and A. Wikforss (2009b). Against normativity again: reply to whiting. [Retrieved: Oct. 10., 2009]. Available from: <http://people.su.se/ kgl/Reply.

Glüer, K. and A. Wikforss (2009c). The normativity of meaning and content. In E. N. Zalta (Ed.), The Stanford Encyclopedia of Philosophy (Winter 2010 Edition). URL = $<$ http://plato.stanford.edu/archives/win2010/entries/meaningnormativity $/>$.

Glüer, K. and A. Wikforss (2013). Against belief normativity. In T. Chan (Ed.), The Aim of Belief, pp. 80-99. Oxford: Oxford University Press.

Glüer, K. and A. Wikforss (2015). Meaning normativism: Against the simple argument. Organon F 22(1), 63-73.

Glock, H.-J. (1992). Wittgenstein vs. Quine on logical necessity. In S. Teghrarian, A. Serafini, and J. Hintikka (Eds.), Wittgenstein and contemporary philosophy, pp. 154-186. Wakefield, NH: Longwood Academic.

Hattiangadi, A. (2006). Is meaning normative? Mind \& Language 21(2), 220240.

Hattiangadi, A. (2007). Oughts and thoughts: rule-following and the normativity of content. Oxford \& New York: Oxford University Press. 
Hattiangadi, A. (2009). Some more thoughts on semantic oughts: a reply to daniel whiting. Analysis $69(1), 54-63$.

Johnson-Laird, P. (2006). How We Reason. Oxford: Oxford University Press.

Kripke, S. A. (1982). Wittgenstein on rules and private language: an elementary exposition. Cambridge, Mass.: Harvard University Press.

MacFarlane, J. (2005). Making sense of relative truth. Proceedings of the Aristotelian Society 105(3), 305-323.

MacFarlane, J. (2014). Assessment Sensitivity: Relative Truth and its Applications. Oxford: Clarendon Press.

McDowell, J. (1984). Wittgenstein on following a rule. Synthese 58(3), 325-363.

Millar, A. (2004). Understanding people: normativity and rationalizing explanation. Oxford: Clarendon Press.

Pothos, E. M. (2007). Theories of artificial grammar learning. Psychological Bulletin 133(2), 227-244.

Sellars, W. (1967). Some reflections on thoughts and things. Nous 1(2), 97-121.

Stalnaker, R. C. (1997). Reference and necessity. In B. Hale and C. Wright (Eds.), A Companion to the Philosophy of Language, pp. 534-554. Blackwell.

Whiting, D. (2007). The normativity of meaning defended. Analysis 67(2), $133-140$.

Whiting, D. (2009). Is meaning fraught with ought? Pacific Philosophical Quarterly 90(4), 535-555.

Yalcin, S. (2011). Nonfactualism about epistemic modality. In A. Egan and B. Weatherson (Eds.), Epistemic Modality, pp. 295-332. Oxford: Oxford University Press. 
Yalcin, S. (2014). Semantics and metasemantics in the context of generative grammar. In A. Burgess and B. Sherman (Eds.), Metasemantics: New Essays on the Foundations of Meaning, pp. chap. 1. Oxford: Oxford University Press.

Yamada, M. (2010). Rule following: A pedestrian approach. Philosophy and Phenomenological Research 80(2), 283-311. 